\title{
Surgical decision-making: can patients benefit?
}

\author{
Ming Liu, Baocai Xing \\ Key Laboratory of Carcinogenesis and Translational Research (Ministry of Education/Beijing), Hepatopancreatobiliary Surgery Department I, \\ Peking University Cancer Hospital \& Institute, Beijing, China \\ Correspondence to: Baocai Xing, MD. Key laboratory of Carcinogenesis and Translational Research (Ministry of Education/Beijing), Hepatopancreatobiliary \\ Surgery Department I, Peking University Cancer Hospital \& Institute, 52 Fucheng Road, Haidian District, Beijing, China. Email: xingbaocai88@sina.com.
}

Submitted Jul 21, 2021. Accepted for publication Jul 31, 2021.

doi: $10.21037 / \mathrm{hbsn}-2021-16$

View this article at: https://dx.doi.org/10.21037/hbsn-2021-16

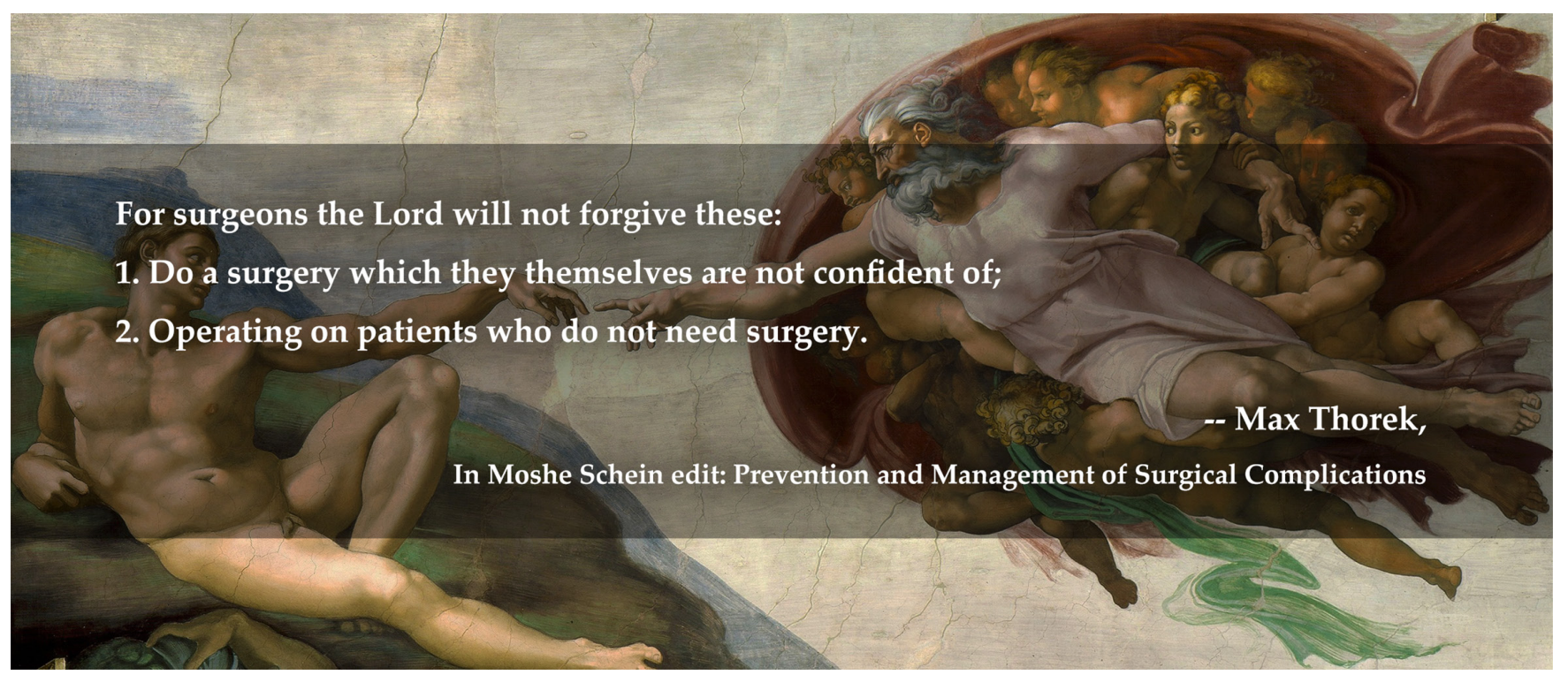

What is surgery? It is difficult for us to have time to think about this broad question in our busy, day-to-day work. In some "super hospitals", patient admission and surgical operation have even become an "assembly-line" job. When a patient successfully recovers from an operation without any postoperative complications, we may be silently proud of our surgical skills. However, when the patient encounters serious postoperative complications or even death, we must pause and reflect: what does the operation bring to the patient? What is the purpose of an operation? What kind of patients should undergo surgery?

In fact, if we look back at the history of surgery, we can find clear answers to these questions.

The earliest known surgical operations were performed to stop the bleeding of injured gladiators. Later, doctors invented amputation in order to save soldiers' lives, which became the major type of operation in the early days. We can certainly imagine how terrifying an amputation could be when there was no anesthesia, with the operation being space filled with the patient's screams. Surgery was once a brutal exercise, which was obviously contrary to the original intention of surgical treatment. Since then, doctors have made unremitting efforts to relieve the surgery-related pain of patients. They gradually discovered the three principles 
of surgery-anesthesia, hemostasis, and disinfectionwhich ensured the safety of operations and enabled surgical techniques to develop rapidly. Surgery has thus become an effective medical treatment.

With the improvement of operation safety, surgeon's deeper understanding of anatomy, and the innovation of imaging equipment and surgical instruments, the indications of surgery have largely expanded, and we have now entered the era of surgery. Many previously unimaginable treatments have now become possible. For example, cardiac surgery was once considered impossible for patients with cardiac diseases because of the inability to stop the heart and operate. The creation of the cardiopulmonary bypass system made this dream a reality. Surgeons can also save patients with liver failure caused by hepatitis or severe cirrhosis through liver transplantation. Furthermore, kidney transplantation, with is completed in more 10,000 patients in China annually, has also matured as a treatment for patients with uremia.

Therefore, the ultimate goal of surgical operation is to help patients. All the developments of surgical techniques, including anesthesia, hemostasis, etc. are to serve the needs of patients. Regardless of whether an operation is simple or complex, the purpose of any operation is to benefit the patient, in either extending the patient's survival time or improving the patient's quality of life. This ethic is echoed in the core tenets of the Hippocratic oath: always come for the benefit of the sick and keep them from harm and injustice (1). Through keeping the oath in mind, doctors can clarify and simplify many decision-making processes in their daily work.

Furthermore, as the safety of surgery and surgical technology rapidly improve and develop, surgeons should be increasingly cautious of surgery's "double-edged" nature: it can remove tumors and treat diseases but it can also affect the physical integrity of the patient's body, cause postoperative trauma and complications, and even lead to death. To minimize the negative aspects of surgery, surgeons need to know that other medical specialties are also rapidly developing. For example, in internal medicine, targeted therapy combined with immune therapy has prolonged the survival time of cancer patients by multiple times. Before deciding to perform surgery for the patient, surgeons must seriously consider the following two questions: (I) will the surgery bring survival benefits to the patient or improve the quality of life? (II) Compared with that of treatment from other medical specialties, is the survival benefit conferred by surgery the greatest? In cases of equal benefit, can surgery provide the least amount of injury to the patient?
To answer these questions, surgeons need to be persistent in learning and enriching their knowledge. Surgeons should not only be proficient within his/her own field of surgery but also keep abreast of the development of other fields. Multidisciplinary diagnosis and treatment (MDT) should be actively pursued because a good surgeon knows that "there are things that must be done and things that must not be done".

One example of what "must be done" is from colorectal liver metastasis (CRLM). Many patients may have more than 10 sites of CRLM when initially diagnosed, and some patients may even have 40-50 sites. Should these patients be treated actively or palliatively? A large number of clinical studies have shown that CRLM is a special type of advanced disease with good biological characteristics. On the premise that systemic treatment is effective, if patients can reach a no-evidence-of-disease state after surgical resection, patients can have significant survival benefits (2). Professor Adam has even suggested that tumor reduction surgery for such patients may also be effective (3), so these patients should be actively treated with operation.

Conversely, an example of what "must not be done" is from pancreatic liver metastasis, which is also an advanced disease. Today's surgical techniques can remove all tumors accurately and safely, and patients can reach the R0 state via pancreaticoduodenectomy with liver resection. However, can these patients' survival time be prolonged through the surgery? In the absence of effective systemic therapy, the answer is no; thus, these patients should not have surgery (4) or should not consider surgery as their primary option. Another example of this is in patients with hepatocellular carcinoma with portal vein tumor thrombus, for whom the median survival time when undergoing surgery is only 6 months even when R0 resection is attained (5); meanwhile, targeted therapy combined with immune therapy alone can attain 8 months of survival, and the median survival time can even be extended by combining radiation and interventional therapy. Therefore, in these patients, operation may not be appropriate.

Furthermore, in patients with unresectable pancreatic head cancer with obstructive jaundice, the primary goal is to resolve the jaundice. In the past, surgeons usually performed biliary-enteric anastomosis for these patients. Nowadays, minimally invasive endoscopic stenting can achieve the same effectiveness (6). Surgery should also not be considered as the primary choice for these patients. This is another example of what "must not be done".

Therefore, in order to make the most appropriate 
suggestions to patients, surgeons must not only continue to learn and be knowledgeable but also actively participate in and promote MDT. If every doctor in the MDT team can think for the benefit of the patient and carefully weigh the advantages and disadvantages of the treatment plan, then, regardless of outcome, the patient has already received the best treatment possible.

In summary, surgeons should keep in mind that surgery was originally created and developed to meet the needs of patients. "Patient-centered treatment" is the basic principle for making any medical decision and can inform whether to operate, when to operate, and how to operate. A surgeon who simply masters the necessary surgical techniques cannot yet be recognized as a competent surgeon. We should continue to learn, conduct research, and cooperate with other specialists to understand "the things that must be done, and the things that must not be done". We must do the best we can, and move forward.

\section{Acknowledgments}

Funding: None.

\section{Footnote}

Provenance and Peer Review: This article was commissioned by the editorial office of Hepatobiliary Surgery and Nutrition. The article did not undergo external peer review.

Conflicts of Interest: Both authors have completed the ICMJE uniform disclosure form (available at https://hbsn. amegroups.com/article/view/10.21037/hbsn-2021-16/coif). The authors have no conflicts of interest to declare.

Ethical Statement: The authors are accountable for all aspects of the work in ensuring that questions related to the accuracy or integrity of any part of the work are appropriately investigated and resolved.

Open Access Statement: This is an Open Access article distributed in accordance with the Creative Commons Attribution-NonCommercial-NoDerivs 4.0 International License (CC BY-NC-ND 4.0), which permits the noncommercial replication and distribution of the article with the strict proviso that no changes or edits are made and the original work is properly cited (including links to both the formal publication through the relevant DOI and the license). See: https://creativecommons.org/licenses/by-nc-nd/4.0/.

\section{References}

1. Hippocrates. The oath. Available online: https://www.nlm. nih.gov/hmd/greek/greek_oath.html. June 15, 2019.

2. Allard MA, Adam R, Giuliante F, et al. Long-term outcomes of patients with 10 or more colorectal liver metastases. Br J Cancer 2017;117:604-11.

3. Adam R, Kitano Y, Abdelrafee A, et al. Debulking surgery for colorectal liver metastases: Foolish or chance? Surg Oncol 2020;33:266-9.

4. Tempero MA, Malafa MP, Al-Hawary M, et al. Pancreatic Adenocarcinoma, Version 2.2021, NCCN Clinical Practice Guidelines in Oncology. J Natl Compr Canc Netw 2021;19:439-57.

5. Wang K, Guo WX, Chen MS, et al. Multimodality Treatment for Hepatocellular Carcinoma With Portal Vein Tumor Thrombus: A Large-Scale, Multicenter, Propensity Mathching Score Analysis. Medicine (Baltimore) 2016;95:e3015.

6. Moss AC, Morris E, Leyden J, et al. Malignant distal biliary obstruction: a systematic review and meta-analysis of endoscopic and surgical bypass results. Cancer Treat Rev 2007;33:213-21.
Cite this article as: Liu M, Xing B. Surgical decision-making: can patients benefit? HepatoBiliary Surg Nutr 2021;10(4):512514. doi: 10.21037/hbsn-2021-16 